\title{
Session 2793
}

\section{En Route to Engineering: Nabokov, Lepidoptera, Dynamics}

\author{
Diana Dabby \\ Franklin W. Olin College of Engineering
}

\begin{abstract}
Developed to help attract underrepresented groups, particularly women, to engineering and science, this first-year seminar introduces students to research, 'just-in-time' learning, and the application of their newly gained scientific knowledge to literature, as they seek answers to the question: To what extent did Nabokov's expertise in Lepidoptera infuse his literary works? In doing so, they examine Nabokov-writer and Nabokov-lepidopterist. Students experience the rewards of speaking a scientific language and the inventiveness that can emanate from its application. In seeing how skillfully Nabokov weaves his art with his science, students may consider engineering, mathematics, and science as complementary to their life and learning aspirations, rather than as unrelated disciplines.
\end{abstract}

\section{Introduction}

Nabokov, Lepidoptera, Dynamics links introductory topics in science and mathematics to the humanities, specifically literature. It serves as an 'attractor' course for women considering engineering as a major - indeed, all of the students in last year's seminar were women - as well as for polymaths (those students having talents and interests in both the arts and sciences). For each of these groups, the coupling of math and science with humanities-related topics broadens the appeal of the disciplines that underpin aspects of engineering practice, namely differential equations and biology.

Not only does the scientific component of the course expose more humanities-oriented students to new concepts and ways of thinking, the literature component allows engineering-focused students a window into a literary world where science still plays a role.

By combining self-teaching, research, discussion, lecture, interdisciplinary thinking, and even humor, the class targets an array of learning styles. At our new college, it has provided an early, successful test of 'just-in-time' learning, showing students the benefits and possibilities that ensue from grasping and applying a scientific topic to an interesting question or problem.

\section{Learning Lepidoptera}

Vladimir Nabokov's passion for Lepidoptera (the order of insects encompassing butterflies and moths) results in a number of butterfly and moth families appearing in his novels - families with names like Lycaenidae, Satyridae, Nymphalidae, Pieridae, (representative of butterflies), and Sphingidae, Noctuidae, Saturniidae, and Geometridae, (representative of moths). These families 
fit into the taxonomic order as follows: class (Insecta), order (Lepidoptera), family, genus, species, subspecies. A definition only exists for species (the capability to interbreed and produce viable offspring), which means that classifications other than species often prove contentious.

A crash tutorial on Lepidoptera serves as a model for student self-teaching and exposes them to the merits of 'just-in-time learning'. An understanding of how butterflies and moths are engineered for survival - their anatomy, behavior, sensory systems, and life cycle — proves crucial for any ties they may make between Nabokov's literary works and Lepidoptera. Students apply this knowledge throughout the course; in effect, they have learned a new language. Much of the crash tutorial is self-taught and researched so students experience how to teach themselves a topic necessary for approaching Nabokov from a cross-disciplinary perspective, much as engineers and scientists teach themselves new topics and skills as dictated by their research.

As part of the crash tutorial on Lepidoptera, students research butterflies and moths, attend lectures on the topic, and present their findings to the class. One such series of presentations required each student to choose a butterfly or moth family, and write its "biography", with an ear towards presenting the chosen family to the rest of the class in an engaging way. The same material (life cycle, mating habits, social behavior) is often covered from a variety of perspectives, depending on the family being discussed, thus fostering a deeper understanding and an appreciation for the broad concepts evident in lepidopterology.

As detectives on a Lit/Lep hunt, students read Nabokov's autobiography (Speak, Memory), The Gift, Lolita, and Pale Fire, seeking out all possible references to butterflies and moths. What they find illuminates the role of Nabokov's other life-his obsession with Lepidoptera-embedded within his literary life. Nabokov's distinctive literary voice cannot be separated from his Lepidoptera. As a lepidopterist he authored nine journal papers (seven of them in Psyche and The Entomologist) that contributed to the science of lepidopterology, specifically in the taxonomic classification of various genera in the Lycaenidae family.

\section{Lep Soap Operas}

In order to aid retention and spark deeper interest in the underlying science, the class continues to pursue Lepidoptera beyond the crash tutorial, sometimes in a humorous way. What goes on in a lepidopteran's world can reveal both high (and low) drama. The course uses true tales-featuring Lep Wannabes, All My Children, and Lep Cross-Dressers-to further build the biological knowledge base necessary for equipping students to apply that science to literature. As Nabokov remarks in his autobiography, "It is astounding how little the ordinary person notices butterflies." The crash tutorial plus the continuing pursuit of Lepidoptera beyond the tutorial cannot be overemphasized. Together they provide the tools for students' detective work as they seek answers to the question: to what extent (if any) did Nabokov's ability and knowledge in lepidopterology inform his literary work?

Mimicry (featuring Lep Wannabes and Lep Cross-Dressers)

Certain butterflies and moths, poisonous to vertebrates, enjoy protection from predators that 
other Lepidoptera might emulate. After a few distasteful experiences, predators 'learn' through visual clues not to bother with certain species. The poisonous species can become models for nonpoisonous species through evolution whereby the non-poisonous species mimic poisonous leps in general appearance. Models are always poisonous. Mimics can be poisonous (known as Müllerian mimics) or edible (Batesian mimics). Clearly, the number of Batesian (nonpoisonous) mimics that flourish can affect the welfare of both model and mimic: too many edible mimics can

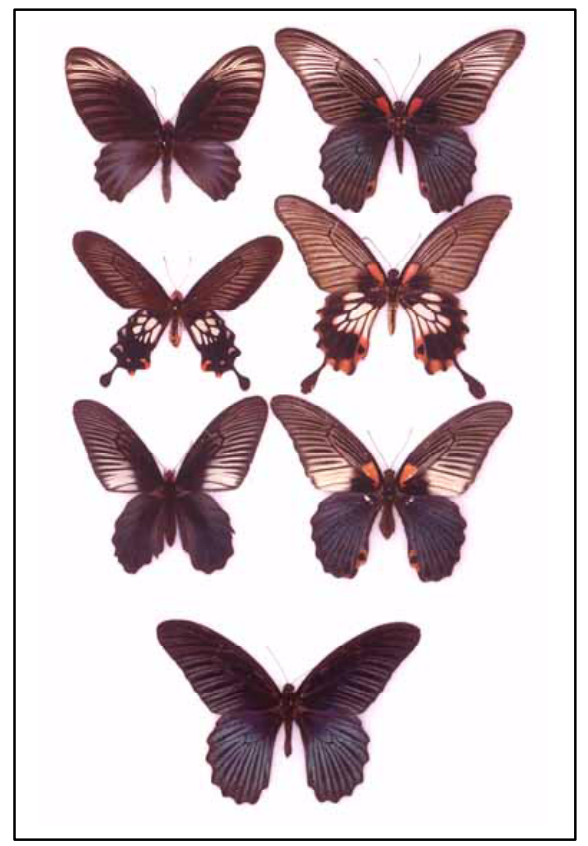
re-teach the predator that unpleasant side effects will not always follow a hearty meal. Thus, Batesian mimicry often occurs in only one sex, the female, which halves the number of possible mimics. Evolution targets the female so that predation reduces egg count as well.

In the figure, three unpalatable swallowtail models (all male) appear on the left with their mimics, all 'Lep Wannabes', on the right. In this case, all three mimics on the right are female, palatable, i.e., Batesian. The lone butterfly at the bottom represents Papilio memnon male, given for purposes of comparison.

"Lep Cross-Dressers" presents another twist on mimetic disguise - the actual impersonation of a nonLep — as described in Speak, Memory:

The mysteries of mimicry had a special attraction for me. Its phenomena showed an artistic perfection usually associated with man-wrought things. ... When a certain moth resembles a certain wasp in shape and color, it also walks and moves its antennae in a waspish, unmothlike manner. When a butterfly has to look like a leaf, not only are all the details of a leaf beautifully rendered but markings mimicking grub-bored holes are generously thrown in.

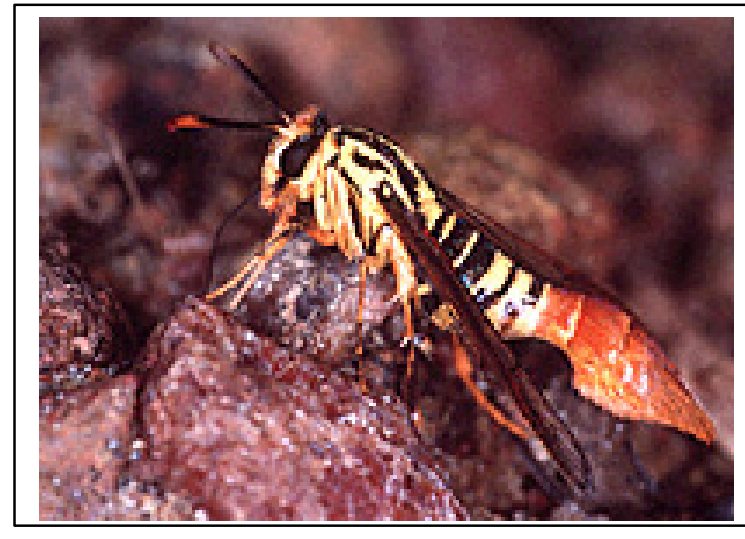

A wasp mimic moth

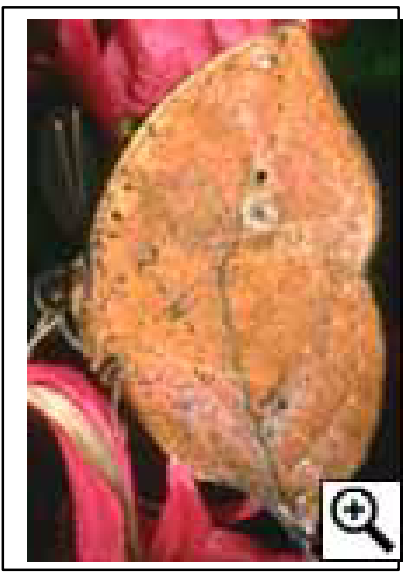

A leaf buttterfly

Mimicry, incorporating deception through imitation, plays a prominent role in Lolita, where the 
12-year old Lolita mimics her mother and Humbert (Lolita's pedophile stepfather) mimics an upstanding citizen of the community, as discussed later. The Lep Soap Operas, utilizing particularly memorable and dramatic depictions of models, mimics, and non-Lep imitators, help students retain key information which they can later use to make connections between Nabokov's literary work and his Lepidoptera.

Betrayal ("All My Children")

As in the autobiography, an uninterrupted section of The Gift concerns butterflies and moths, revealing the wonderment and delight these creatures stir in the protagonist and narrator, Fyodor Godunov-Cherdyntsev, as he relates what his naturalist father taught him:

He taught me how to take apart an ant-hill and find the caterpillar of a Blue [a butterfly in the Lycaenidae family] which had concluded a barbaric pact with its inhabitants, and I saw how an ant, greedily tickling a hind segment of that caterpillar's clumsy, sluglike little body, forced it to excrete a drop of intoxicant juice, which it swallowed immediately. In compensation it offered its own larvae as food; it was as if cows gave us Chartreuse and we gave them our infants to eat. ${ }^{2}$

This Blue, most probably the Large Blue ${ }^{3}$, produces a caterpillar that, after feeding on its hostplant, allows itself to be carried into an anthill. The ants offer protection from a potentially hostile environment and their own ant larvae as food. In return, the caterpillar secretes sweet juice that the ants cannot resist. Such a scenario evokes the plot of Lolita.

\section{Making Connections as a Stimulus to Student Learning and Understanding}

When students take a step back and look at Lolita as a whole, the descriptive quote given earlier (concerning the larvae-eating caterpillar from The Gift) naturally comes to mind. Like the Lycaenidae caterpillar's barbaric pact with the ant colony (trading sweet juice for ant larvae), Humbert enters the Haze household, exuding a French charm that Charlotte Haze (Lolita's mother) finds irresistible. But like the Lycaenidae caterpillar, Humbert's only intent is to "feast" on her offspring.

Through their study of the biological phenomenon of mimicry, students make the connection between mimicry and what transpires in the Haze household. In an early scene, Nabokov places a potential model (Charlotte), mimic (Lolita), and predator (Humbert) in the sunbathing 'piazza' or garden-patio of the Haze home.

This time I took up a strategic position, with obese newspaper and new pipe, in the piazza rocker before L. arrived. To my intense disappointment she came with her mother, both in two-piece bathing suits, black, as new as my pipe. ... As I looked on, through prismatic layers of light, dry-lipped, focusing my lust and rocking slightly under my newspaper, I felt that my perception of her, if properly concentrated upon, might be sufficient to have me attain a beggar's bliss immediately; but, like some predator that prefers a moving prey to a motionless one, I planned to have this pitiful attainment coincide with one of the various girlish 
movements she made now and then as she read ... ${ }^{4}$ [emphasis mine]

Charlotte (ignored by Humbert as a 'distasteful' model) already feels threatened by Lolita (her 'edible' Batesian mimic), as revealed by Humbert:

... for almost three weeks I had been interrupted in all my pathetic machinations.

The agent of these interruptions was usually the Haze woman (who, as the reader will mark, was more afraid of Lo's deriving some pleasure from me than of my enjoying Lo). [emphasis mine]

And indeed, as long as Charlotte remains alive, Lolita seems to revel in teasing and playing with Humbert, a man 25 years her senior. She probably knows that her deceased father Harold Haze was 20 years Charlotte's senior. By focusing on Humbert, as well as on Clare Quilty (an earlier romantic interest of her mother's), Lolita mimics Charlotte, yet in her own girlish way. While riding alone in a car with Humbert, and before she knows her mother has died, Lolita exclaims: "Say, wouldn't Mother be absolutely mad if she found out we were lovers?"

In the lep world, models and mimics fly more slowly, less 'skittishly', than other butterflies, as if they sense their protective immunity to predators. But if the model dies, all protection for the mimics vanishes - it is just a matter of time before the mimic becomes prey. When Lolita realizes her mother is dead, that vulnerability becomes palpable. Any protection Charlotte may have offered to counter Humbert, a self-acknowledged predator, is gone. In fact, Lolita is clearly upset, as Humbert reveals, "...her sobs in the night - every night, every night — the moment I feigned sleep."

At this point, students recall the Batesian mimics (the Lep Wannabes), and make the connection of Charlotte as model and Lolita as her non-poisonous mimic. In Humbert's eyes, Charlotte has always been 'unpalatable'. Lolita is now very 'edible', available, and with no protection whatsoever. The model has died, leaving the mimic vulnerable to predation.

Charlotte may also serve as a model for Humbert in terms of how he relates to her daughter. When Charlotte discovers Humbert's diary, rife with his aversion to her and his lust for Lolita, Humbert insists "It is all your hallucination. You are crazy, Charlotte. The notes you found were fragments of a novel." In a similar manner, Lolita later attacks Humbert for his crazy imagination, though she is lying to him just as he lied to her mother. In part I of the novel, Lolita mimics her mother, while the relationship between mother and daughter and the relationship between Humbert and Charlotte acquire dimension. In part II, Humbert gradually comes to mimic Charlotte (frustrated and possessive) while Lolita mimics Humbert (averse and detached).

Whether Nabokov would agree with such interpretations can stir intense debate. Certainly Alfred Appel in his annotations to Lolita makes no mention of such models/mimics, ${ }^{5}$ nor do other scholars $^{6,7}$ (some of whom have elicited pointed dismissals from Nabokov on other lepidopteral links). Yet Humbert does mention mimicry and he does so overtly.

Although I could never get used to the constant state of anxiety in which the 
guilty, the great, the tenderhearted live, $\underline{\text { I felt I was doing my best in the way of }}$ mimicry. ... I watched ... Dr. Humbert see his daughter off to school. I watched him greet with his slow smile and pleasantly arched thick black ad-eyebrows good Mrs. Holigan, ... [emphasis mine]

These lepidopteral links keep students probing, pondering, and making connections. In doing so, they exercise their ability to argue and support claims and counterclaims. By using scientific fact and literary perception, they address the question of how Nabokov engineers his novels.

Finally, one more drama plays out in the butterfly world that bears a relationship to Lolita. The Zebra Longwing, a member of Family Nymphalidae, displays mating habits that recall the plot enveloping Humbert and his charge. Shortly before a female longwing emerges from her pupa casing, males surround the pupa, detecting her scent. As she emerges, they fight for the chance to mate with her. Unlike the courtly behavior of other lepidopteral mating rituals, where the female dances a pas de deux with the male or at least has the option of rejecting a potential mate, the female longwing, weak after emergence, cannot fight off any advances. The mating habits of the Zebra Longwing present a natural parallel to the statutory rape of Lolita by Humbert.

Student learning, understanding, and their appreciation for the intricacies of bioscience soar when they apply the biology they have learned to literature: they realize that their scientific knowledge enables them to hypothesize and support an analytical link between the phenomenon of mimicry and characterization in Lolita. They actively experience the application of two languages in order to make connections. That act of making connections due to their scientific understanding (selftaught!) not only builds confidence but also shows the rewards and power of the scientific discipline. The students have become 'literary engineers' through the application of scientific knowledge to a literary problem or question: to what extent does Nabokov's knowledge of Lepidoptera infuse his art, and if so, how is this knowledge manifested?

That Nabokov planted lepidopteral gems for the delight of careful readers does not appear farfetched given the author's penchant for discovery, both in his science and in his literary criticism. ${ }^{8}$ Students on their lit/lep hunt through Lolita engage in the kind of detective work Nabokov relished. In doing so, they uncover tangles and leads, sometimes true, sometimes false, sometimes quite unknowable - not unlike the research they may one day do in engineering.

V. Moths and DiffEqs

Since students study Lepidoptera throughout the course, introducing diffeqs via moths becomes an intuitive next step. First year engineering students who have had only a semester of calculus can actually make connections that take them from Lepidoptera into the realm of differential equations. A caterpillar of the Tortricidae moth, Choristoneura fumiferana, attacks the leaves of the balsam fir. During an outbreak, these caterpillars can defoliate and kill most of the forest firs in roughly four years. Such an outbreak can be predicted from the model ${ }^{9}$

$$
d x / d t=r x(1-x / k)-x^{2} /\left(1+x^{2}\right)
$$


where $x$ represents the population of the caterpillars Choristoneura fumiferana, $r>0$ is the growth rate, and $k>0$ designates the carrying capacity of the forest which depends on the amount of foliage available. By analyzing the model qualitatively, students come to understand the ecological dynamics between the caterpillars and the forest firs. Addressing the question 'what exactly is a differential equation and what is it telling us' ensues from a simple graphical analysis. Since the right hand side (RHS) of the equation gives the slope of the tangent line to the graph of $x$, students can determine whether the population is growing or decreasing by ascertaining whether the RHS is positive or negative for different values of $x$. Students can graph each of these RHS terms, noting where $x^{2} /\left(1+x^{2}\right)>r x(1-x / k)$, indicating the population is decreasing, and where $r x(1-x / k)>x^{2} /\left(1+x^{2}\right)$, signifying the increasing population.

The values of $x$ that satisfy the equality $x^{2} /\left(1+x^{2}\right)=r x(1-x / k)$ give the fixed points of the system, i.e., those portions of the phase line where the population $x$ does not change. Three nontrivial fixed points exist. Students determine the stability of each by observing where, on the phase line, $x$ is increasing and where it is decreasing.

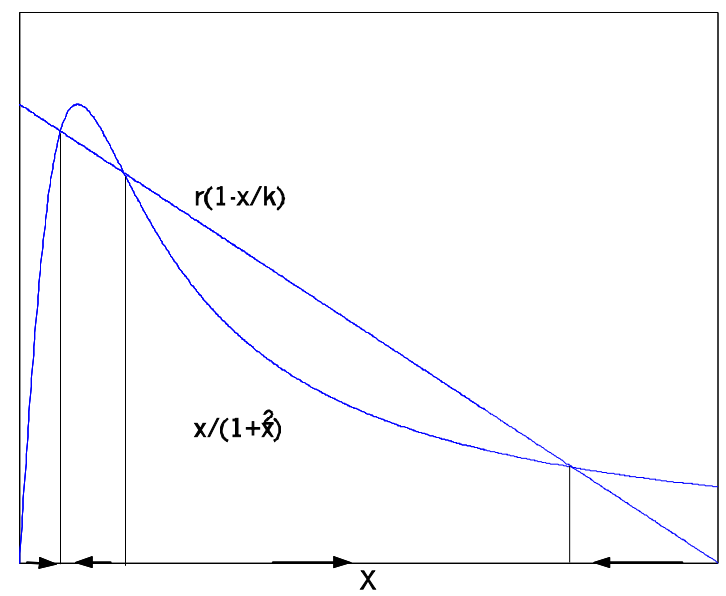

Assuming a carrying capacity of $k=312$ and a growth rate $r=0.5$ (realistic values for a young forest), students can then predict the dynamics of the fumiferana population based on their qualitative model analysis. Furthermore, they have acquired insight into the actual meaning of differential equations via an intuitive, graphical approach.

The women in the class cited the connection between moths and math as a particularly satisfying linkage of what they had learned in earlier math courses (in high school) to their current knowledge base.

\section{Learning Objectives}

More often than not, a wise preamble to a new course starts with posted learning objectives so that students maintain a sure compass as the semester progresses. Here, however, no learning objectives were posted. Rather, at the end of the term, students were asked, in a discussion setting, to state the objectives as they saw them, now that the course was over. They came up with the following list: 
- To ascertain the extent to which Nabokov's knowledge of Lepidoptera infused his work as a writer

- To experience the discovery process, e.g., via research and the Lit/Lep Hunt

- To make connections singly and together: applying scientific knowledge to literary analysis

- To engage in a crash tutorial (in this case Lepidoptera) and immediately apply what was learned (a test case for "just in time" learning)

- To understand Nabokov's use of Lepidoptera-what is its function for the novel at hand?

- To make connections between bioscience and math modeling

Asking students at the close of a course to state the learning objectives can sometimes be a satisfying conclusion for them. Instead of being told what they are to learn, they review for themselves what it is that they actually learned. This review helps them to assess their learning and understanding of the material. It also stimulates retention, an important thread through the course, given the lepidopteral knowledge they must retain and continue to apply. By doing so, they mentally and creatively connect the dots from where they started to where they ended-for each of them, an exciting passage, presenting one final discovery before the end of class.

VII. Assessment

When asked at the end of the term (via Olin's Course Evaluation questionnaire) - "What was the most interesting, surprising or useful skill, knowledge, or idea you learned?"- half of the students cited the connection between the science of lepidopterology and Nabokov's literary works. All of the students marked "strongly agree" to the question, "Considering the WAY the course was designed and taught, this activity encouraged creativity." All also "strongly agreed" that the course helped them to "gain new knowledge about a discipline, field, or methodology." Finally, each member of the class agreed or strongly agreed that the course "stimulated my intellectual curiosity", was "fun", and "motivated me to learn."

The above assessment indicates that pairing science with literature proved to be an engaging activity for the class-all of whom were women. It stimulated their intellect, creative spirit, and helped them to acquire new disciplinary knowledge, in this case-bioscience, mathematics, and literature.

VIII. Conclusion

Nabokov, Lepidoptera, Dynamics entwines bioscience, literature, and mathematics in 
an effort to engage students' creativity, intellectual curiosity, and desire for knowledge-with a goal of attracting women to science and engineering in the freshman year. Women comprised the class, suggesting that the course title and topic proved an initial draw.

All of these women possessed a deep and unwavering love for the humanities in addition to a talent for engineering (as evidenced by their high school transcripts). It is conceivable, then, that such a course might attract polymaths among students in general, adding a more diverse element to engineering student bodies.

Nabokov's literary oeuvre offers a model for the unique work that can result when one goes beyond the narrow focus of a single discipline. It can help engineering students (not only in the first year, but in subsequent years) who often cannot see beyond one problem set to the next to cast a wider net and to realize that it is possible to quickly absorb a topic — and apply it — in order to go beyond the current research in a field. It also can help humanities students to see beyond the next paper and build a reference point in science that may ultimately lead them to more science classes and perhaps to engineering as well.

Bibliographical Notes

${ }^{1}$ Nabokov, V. Speak, Memory. New York: Vintage (1967).

${ }^{2}$ Nabokov, V. The Gift. New York: Vintage (1963).

${ }^{3}$ Email correspondence (2001) with Dieter Zimmer.

${ }^{4}$ Nabokov, V. Lolita. New York: Vintage (1997).

${ }^{5}$ Nabokov, V. The Annotated Lolita. Edited and annotated by A. Appel. New York: McGrawHill (1970).

${ }^{6}$ Butler, D. Lolita Lepidoptera. In Critical Essays on Vladimir Nabokov. Edited by P. roth.

Boston: C.K. Hall (1984).

7 Johnson, D. That butterfly in Nabokov's Eye. In Nabokov Studies (1997), 4, 1-14.

${ }^{8}$ Boyd, B. Nabokov, Literature, Lepidoptera. In Nabokov's Butterflies by V. Nabokov. Edited and annotated by B. Boyd and R. Pyle. Translations by D. Nabokov. Boston: Beacon Press, 2000.

${ }^{9}$ Ludwig, D., Jones, D., and Holling, C. Qualitative analysis of insect outbreak systems: the spruce budworm and forest. Journal of Animal Ecology (1978), 47, 315-332.

DIANA DABBY, Asst. Prof. of Electrical Engineering and Music at Franklin W. Olin College of Engineering, has taught at MIT (electrical engineering), Tufts (music composition), and Juilliard (graduate studies). She received her PhD from MIT (EECS) for her thesis Musical Variations from a Chaotic Mapping. As a pianist and composer, she has had performances in New York at Weill (Carnegie) Recital Hall, Merkin Concert Hall, and in Boston at Jordan Hall, Symphony Hall, as well as Tanglewood. 